\section{Commentary: Addition of} papillary muscle septalization to tricuspid valve repair: Boom or bust?

\author{
Sameer A. Hirji, MD, MPH, ${ }^{\mathrm{a}}$ Laura Seese, MD, MS, ${ }^{\mathrm{b}}$ \\ and Ashraf A. Sabe, MD
}

Functional tricuspid regurgitation (TR) often occurs in the setting of tricuspid valve (TV) annular enlargement and leaflet tethering that can either alter or appear as a consequence of changes in right ventricular geometry. ${ }^{1}$ Similar to the mitral valve, degree of leaflet coaptation and severity of TV regurgitation depends on the complex anatomic relationship between the valvular apparatus and the structure of the heart. ${ }^{1}$ Several studies have reported recurrent or residual rates of TV regurgitation between $10 \%$ and $20 \%$, with TV tethering noted to be an independent predictor of repair failure. ${ }^{1,2}$ In some cases, an annuloplasty-only approach may not be sufficient to prevent long-term disease progression such that the ideal repair for functional TR may combine interventions that address both the annulus as well as the subvalvular apparatus. ${ }^{1,2}$

Couetil and colleagues ${ }^{3}$ describe an innovative surgical technique for papillary muscle septalization in combination with restrictive annuloplasty for a complete TV repair. Because the papillary muscles of the TV can easy be mobilized, the authors utilize pledget-reinforced polytetrafluoroethylene sutures through the base of the anterior papillary muscle and into the septum, which allows for correction of the tenting of the

\footnotetext{
From the ${ }^{\mathrm{a} D i v i s i o n}$ of Thoracic and Cardiac Surgery, Department of Surgery, Brigham and Women's Hospital, Harvard Medical School, Boston, Mass; and ${ }^{\mathrm{b}}$ Department of Cardiothoracic Surgery, University of Pittsburgh Medical Center, Pittsburgh, Pa.

Disclosures: Dr Hirji is a consultant for Encare EIAS system. The other authors reported no conflicts of interest.

The Journal policy requires editors and reviewers to disclose conflicts of interest and to decline handling or reviewing manuscripts for which they may have a conflict of interest. The editors and reviewers of this article have no conflicts of interest.

Drs Hirji and Seese contributed equally to this article.

Received for publication Oct 3, 2021; revisions received Oct 3, 2021; accepted for publication Oct 13, 2021; available ahead of print Oct 19, 2021.

Address for reprints: Ashraf A. Sabe, MD, Division of Thoracic and Cardiac Surgery, Brigham and Women's Hospital, Harvard Medical School, Boston, MA 02115 (E-mail: asabe@partners.org).

JTCVS Techniques 2021;10:289-90

2666-2507

Copyright (C) 2021 The Author(s). Published by Elsevier Inc. on behalf of The American Association for Thoracic Surgery. This is an open access article under the CC BY-NC-ND license (http://creativecommons.org/licenses/by-nc-nd/4.0/).

https://doi.org/10.1016/j.xjtc.2021.10.023
}

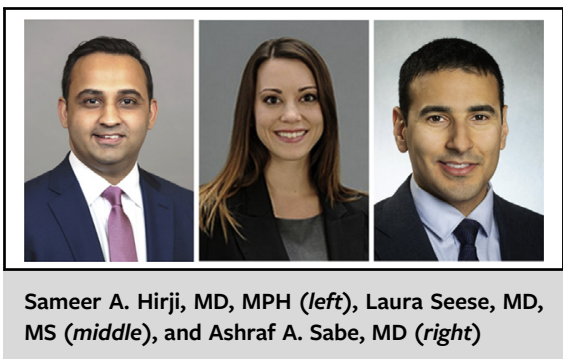

\section{CENTRAL MESSAGE \\ Leaflet tethering predisposes to \\ recurrent, postrepair tricuspid \\ regurgitation. Septalization of the \\ anterior papillary muscle with \\ restrictive annuloplasty may pro- \\ vide an option for holistic repair.}

anterior and posterior leaflets. Although these procedures were performed in 11 patients, 2 patients experienced mortality within 30 days, and 2 required reoperation for recurrent TR. The remaining patients experienced durable tricuspid repairs at 12 months with marked reduction in right ventricular size and pulmonary artery pressures.

The authors are to be congratulated for their innovative approach in the context of TV repair. Similar approaches have been previously described for mitral valve repair. For instance, a randomized controlled trial, also conducted by Nappi and colleagues, ${ }^{4}$ evaluated patients with functional mitral regurgitation who underwent either restrictive annuloplasty alone or in combination with papillary muscle approximation. At 5-year follow-up, there was similar survival with improved left ventricular geometry, less recurrence of mitral regurgitation, and a greater left ventricular ejection fraction in the papillary muscle approximation. Despite these promising results, this technique has not caught much momentum in the armamentarium of mitral valve repair in part due to lack of robust long-term data. Because this technique is also not a standard technique, it also requires a learning-up curve. In the context of TV repair, although the results are encouraging, they are at best hypothesis-generating at this time with lack of longitudinal follow-up, limited data on repair durability, and paucity of comparison to the standard of care. Because right ventricular size, shape, and function are distinctly loaddependent and pulmonary load is an important determinant of right ventricular function in these patients, ${ }^{1}$ whether or not this approach is a boom or a bust remains to be 
determined, especially in the current era of emerging transcatheter technologies for TV. Further studies are required to confirm these preliminary proof-of-concept results.

\section{References}

1. Hahn RT, Waxman AB, Denti P, Delhaas T. Anatomic relationship of the complex tricuspid valve, right ventricle, and pulmonary vasculature: a review. JAMA Cardiol. 2019;4:478-87.
2. Fukuda S, Song JM, Gillinov AM, McCarthy PM, Daimon M, Kongsaerpong V, et al. Tricuspid valve tethering predicts residual tricuspid regurgitation after tricuspid annuloplasty. Circulation. 2005;111:975-9.

3. Couetil J-P, Nappi F, Spadaccio C, Fiore A. Papillary muscle septalization for functional tricuspid regurgitation: proof of concept and preliminary clinical experience. J Thorac Cardiovasc Surg Tech. 2021;10:282-8.

4. Nappi F, Lusini M, Spadaccio C, Nenna A, Covino E, Acar C, et al. Papillary muscle approximation versus restrictive annuloplasty alone for severe ischemic mitral regurgitation. J Am Coll Cardiol. 2016;67:2334-46. 